\title{
VEÍCULO SÉRIE: IMPLANTAÇÃO DO GERENCIAMENTO DA QUALIDADE EM PROJETOS DE PINTURA AUTOMOTIVA
}

\author{
Isabella Novaes Ribeiro \\ UFF - Universidade Federal Fluminense \\ Rua Valdemir de Almeida Viana, Resende, Rio de Janeiro, 27542050, Brasil \\ isabellanribeiro@outlook.com \\ Camila Aparecida Maciel da Silveira \\ UFF - Universidade Federal Fluminense \\ R. Doze, Vila Santa Cecília, Volta Redonda - RJ, 27255-125, Brasil \\ camila.a.silveira@hotmail.com
}

\begin{abstract}
RESUMO
Com o crescimento da indústria automobilística no Brasil, o mercado se faz cada dia mais competitivo, exigindo das empresas preço, qualidade e principalmente itens diferenciados. No ano de 2017 uma montadora de Porto Real decidiu por desenvolver um projeto de reestilização de um veículo série através da pintura automotiva Biton, que deveria ser lançado em nove meses. A direção da empresa estipulou o estilo, tempo e custo do projeto utilizando uma equipe pré-existente da fábrica. Ao longo de seu desenvolvimento muitos problemas de produção e qualidade foram enfrentados sendo necessário o engajamento das pessoas e novas contratações. Este estudo é de natureza aplicada, caracterizado por ter objetivos descritivos e abordagem qualitativa, sendo um estudo de caso. A finalidade deste trabalho é apresentar como foi a implantação do projeto automotivo de pintura biton, seus problemas e soluções referentes ao gerenciamento da qualidade, baseado no guia PMBOK.
\end{abstract}

Palavra-chave: Projeto; PMBOK; Pintura; Biton; Qualidade

\begin{abstract}
The growth of automotive industry in Brazil becomes increasingly competitive, requiring companies price, quality and especially the different types. In 2017, a company in Porto Real decided to develop a restyling project for a automotive paint vehicle, the biton, which should be released in nine months. The direction of the company stipulated the design, the time and costs of the project with a pre-existing factory team. During the project a lot of production and quality problems were faced that new mindset and people were required. This is an applied study, characterized by descriptive criteria and qualitative approach, being a case study. This work presented an implementation of a project of automotive biton, its problem and airsheet based on PMBOK guide.
\end{abstract}

Keywords: Project; PMBOK; Paint; Biton; Quality. 


\section{Como Citar:}

RIBEIRO, Isabella Novaes; SILVEIRA, Camila Aparecida Maciel. Veículo série: Implantação do gerenciamento da qualidade em projetos de pintura automotiva. In: SIMPÓSIO DE PESQUISA OPERACIONAL E LOGÍSTICA DA MARINHA, 19., 2019, Rio de Janeiro, RJ. Anais [...]. Rio de Janeiro: Centro de Análises de Sistemas Navais, 2019.

\section{INTRODUÇÃO}

No final do século XX, uma forte crise financeira tomou conta do cenário mundial, acarretando uma grande perda de lucratividade nas empresas automobilísticas. Devido a esse fato, foi necessária a reestruturação dessas indústrias no cenário mundial, levando a criação de novos sites nos países periféricos. Diversas empresas, como Ford, Volkswagen, Chevrolet, Peugeot, Citröen e Renault, se instalaram no Brasil e tornaram o mercado automobilístico predominante na economia do país, o que levou ao crescimento econômico e acarretou benefícios como a geração de empregos à população, giro de capital entre bancos e empresas e também impostos pagos ao governo.

O Brasil dominou esse cenário até 2012, onde atuou nas primeiras posições do ranking de vendas de veículos leves do mundo e apresentava perspectiva de dobrar em 2025 . Porém, em cenários desfavoráveis, as exigências de qualidade, flexibilidade, desempenho, ergonomia, segurança, diferenciação e redução de custos são buscadas cada vez mais tanto pelas empresas quanto pelos seus consumidores.

Com a competitividade do mercado é necessário que a gestão realize constantemente estudos de melhoria nos processos e soluções de engenharia, implicando na otimização dos recursos e consequentemente na redução de custos sem que seja necessário realizar grandes investimentos.

Com o aumento da concorrência, as empresas precisam se destacar cada vez mais no mercado e para isso, buscam constantemente melhorias a fim de se tornarem mais competitivas frente aos seus concorrentes. Sem a devida dedicação ao processo de melhoria contínua a sobrevivência das organizações pode ficar comprometida.

Para o setor automobilístico lançar novos produtos baseados na exclusividade e no diferencial é essencial. Para auxiliar o desempenho dos projetos diários das empresas o gerenciamento de projetos se torna necessário no planejamento e execução, fazendo parte dos objetivos estratégicos de uma organização. Quase um terço do PIB da economia mundial é gerado por meio de projetos (Tuner, 2008). Oliveira et al., (2016) sintetizam projeto como um empreendimento exclusivo, com um começo e um fim, estabelecido sob um objetivo bem definido, que consome recursos e opera sob pressão de prazos, custos e qualidade. Em relação ao esforço, considera um empreendimento que exige de seus interlocutores, atenção aos meios, competência para lidar com procedimentos, regras e integração de pessoas.

Em organizações governamentais, institucionais e industriais existe um reconhecimento crescente que, embora muitos projetos existam, eles são pouco compreendidos e mal gerenciados (Archibald, 2003). De acordo com Oliveira et al. (2016) são poucas as pesquisas em gerenciamento de projetos, identificando-se um movimento constante sobre as diversas perspectivas do conhecimento existente na disciplina, que impulsiona os estudos em gerenciamento de projetos e constitui potencialidades de pesquisa na temática.

Devido à queda nas vendas e o baixo percentual de presença no mercado brasileiro, uma montadora de Porto Real decidiu por investir em trabalhos de engenharia atrelado a uma nova tecnologia para um modelo de veículo lançado a anos atrás, a pintura automotiva biton. 
Com isso, uma equipe de projetos já formada anteriormente foi reconduzida para iniciar os estudos dessa reestilização, que em nove meses teve que estar no mercado.

Este trabalho possui natureza aplicada, objetivos descritivos e abordagem qualitativa, sendo um estudo de caso. A metodologia utilizada está baseada no levantamento do referencial teórico sobre os temas gerenciamento de projeto e suas áreas do conhecimento. Após o levantamento, contextualizou-se os principais processos envolvidos no estudo. A finalidade deste trabalho é apresentar como foi a implantação do projeto automotivo de pintura biton, seus problemas e soluções referentes ao gerenciamento da qualidade, baseado no guia PMBOK.

\section{IMPORTÂNCIA E BENEFÍCIOS DO GERENCIAMENTO DE PROJETOS}

Segundo Project Management Institute (PMI) o gerenciamento de projetos é "a aplicação de conhecimento, habilidades, ferramentas e técnicas às atividades do projeto a fim de atender aos seus requisitos". O PMBOK (PMI, 2017), divide o gerenciamento de projeto em dez áreas (Figura 1) agrupadas por requisitos de conhecimento.

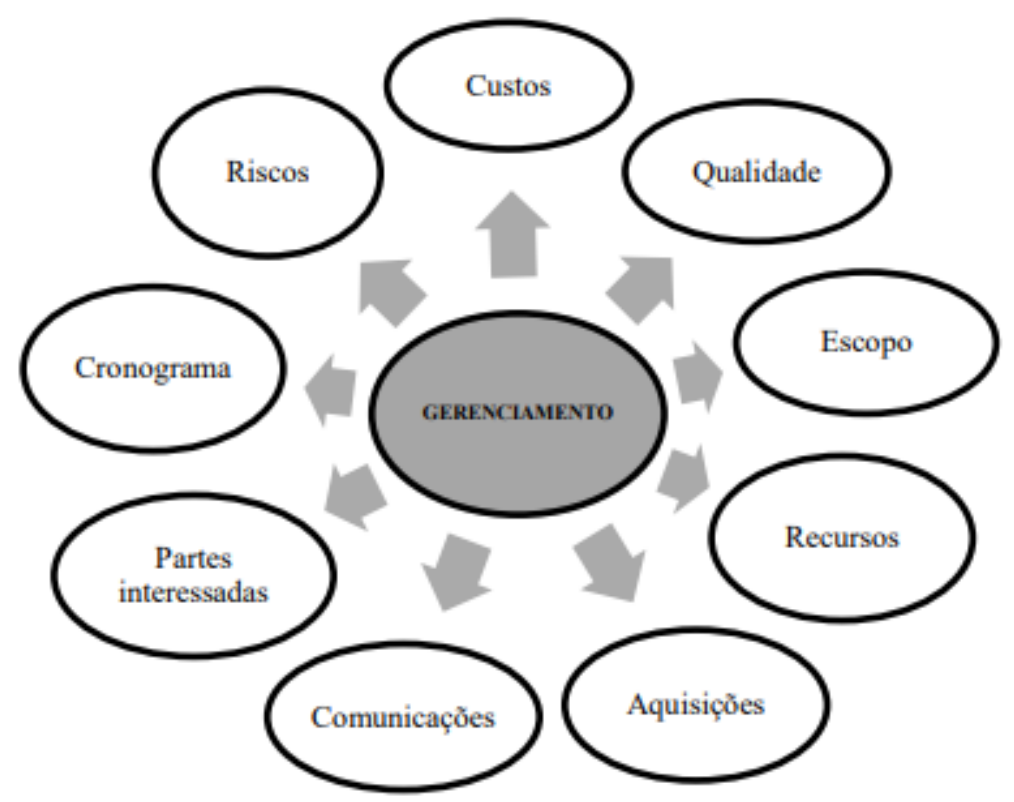

Figura 1 - Áreas do gerenciamento de projetos (PMI, 2017).

- Escopo: processos necessários para assegurar que o projeto inclua todo o trabalho, para que o mesmo termine com sucesso. Está relacionado com a definição e controle do que está ou não está incluso no projeto, podendo ser produto, serviço ou resultado. Além disso, é área onde defini os critérios para determinar se o projeto já foi ou não completado.

- Custo: gera estimativas e previsões de custos totais do projeto afim de garantir que todo o recurso financeiro necessário para a realização do empreendimento esteja disponível. Preocupa-se com os custos dos recursos, retorno do investimento, fluxo de caixa descontado e análise da recuperação do investimento.

- Recursos: processos para identificar, adquirir e gerenciar os recursos necessários para a conclusão bem-sucedida do projeto. Esses processos auxiliam a garantir que os recursos definidos estarão disponíveis para o gerente de projeto e sua equipe na hora e lugar certo. Os recursos a serem geridos podem ser em relação a recursos físicos, que incluem equipamentos, materiais, instalações e infraestruturas ou recursos humanos, o qual são definidos os tipos e perfis profissionais que farão parte da equipe, onde e em qual etapa 
deverão estar presentes, bem como sua hierarquia e matriz de responsabilidade.

- Cronograma: é responsável por estimar os recursos, a duração e a sequência das atividades do projeto. É definido através dele o cronograma do projeto e posteriormente as atividades e pendências.

- Riscos: é o processo de condução do planejamento, com a identificação, análise e monitoramento dos riscos do projeto. O principal objetivo é aumentar a probabilidade de eventos positivos e reduzir a probabilidade dos impactos negativos. Dessa forma é gerada uma lista de riscos previamente identificados, classificando sua criticidade e possibilidade de ocorrência, onde a partir de então os riscos passam a ser controlados e monitorados para que o projeto possa ocorrer dentro do planejado.

- Integração: processos e atividades que buscam identificar, definir, combinar, unir e coordenar os demais processos do gerenciamento de projetos dentro do Grupo de Processos de Gerenciamento de Projetos afim de garantir uma boa gestão.

- Comunicações: inclui os processos necessários para garantir que as necessidades das informações do projeto $\mathrm{e}$ de suas partes interessadas sejam satisfeitas com o desenvolvimento de artefatos e a implementação de atividades projetadas para realizar a troca eficaz de informação. Ou seja, ele assegura o desenvolvimento, recuperação, distribuição, recolhimento, armazenamento e destinação final das informações sobre o projeto de forma adequada e oportuna.

- Aquisições: processos necessários para comprar ou adquirir produtos, serviços ou resultados externos a equipe de projeto. Se trata da área a qual defini o que se deve adquirir, quem e quando. É baseado no controle, desenvolvimento e administração dos acordos, como contrato, memorandos, pedidos de compras ou acordos. Essa gestão pode ser feita não só pelos gerentes de projetos, como também por membros da equipe ou departamento de compras.

- Partes Interessadas: identificação das pessoas, grupos e organizações que podem impactar ou serem impactados pelo projeto. São analisadas as expectativas das partes interessadas, seu desenvolvimento e estratégias para o engajamento eficaz das decisões e execução do projeto. Todos os projetos têm partes interessadas que são afetadas, tanto de forma positiva quanto negativa, sendo algumas com capacidade limitada e outras com influência significativa, por isso é fundamental conhecer a opinião dos stakeholders, manter empatia e uma boa imagem da empresa frente ao mercado.

- Qualidade: processos para incorporação da política da qualidade da organização com relação ao planejamento, gerenciamento e controle dos requisitos de qualidade do projeto para atender os objetivos das partes interessadas. Tem como responsabilidade garantir que o projeto atinja todos os objetivos e funções os quais foi determinado. São definidos padrões e normas de qualidade afim de assegurar a melhoria continua onde são realizadas auditorias fiscalizando 5 se tudo está sendo cumprido. Este estudo destaca o gerenciamento da qualidade nos processos de pintura automotiva.

As necessidades dos projetos sofrem alterações ao longo do tempo, exigindo uma avaliação crítica das práticas e conhecimentos convencionais de GP prescritas pelos praticantes (Cicmil et al., 2006). O gerenciamento de projetos (GP) evolui com as exigências do mercado possuindo características como equipes auto gerenciadas e com autonomia para tomar decisões, planejamento limitado, escopo mínimo com abertura para as mudanças, ênfase na velocidade, iterações de colaboração no trabalho e envolvimento do cliente (Conforto, 2014). A prática de gerenciamento de projetos é consequentemente vista como uma conduta social, definida pela história, contexto, valores organizacionais e estruturais (Cicmil et al., 2006).

A aceitação das necessidades de alterações das tecnologias no ambiente de trabalho requer mudanças nos processos, na estrutura e na cultura (Nach, 2016). O GP se expande 
para incluir cada vez mais as áreas como estratégia, tecnologia, comercial e também as pessoas, pois "os projetos são construídos por, com e para as pessoas" (Morris, 2010).

Com o PMBOK (PMI, 2017), o sucesso deve ser medido pela qualidade do produto e do projeto, junto a sua pontualidade, cumprimento do orçamento e grau de satisfação do cliente. O Instituto de Gerenciamento de Projetos afirma que 20\% do Produto Interno Bruto (PIB) do mundo é investido na execução de todos tipos de projetos. São 12 trilhões de dólares destinados a melhoria, criação ou construção de algo, por meio da gestão de projetos. Assim, se trata de um item fundamental para as empresas que buscam se destacar frente a concorrência.

Segundo o PMBOK (PMI, 2017), "projeto é um esforço temporário empreendido para criar um produto, serviço ou resultado exclusivo". Pesquisas realizadas pelo PMI-RJ têm demonstrado que $72 \%$ dos projetos apresentam impacto na data de aplicação quando não implementadas as técnicas do gerenciamento de projetos. Além do não cumprimento do prazo que acarreta em problemas de custos, gera perda de credibilidade do cliente e desmotivação da equipe. Na mesma pesquisa foi apontado que $82 \%$ das empresas estão dispostas a investirem na área de gerenciamento de projeto, trabalhando no seu desenvolvimento e metodologia afim de ganhar competitividade no contexto atual do mercado.

Em projetos é preciso criar, ser singular, ousar (Carvalho et al., 2005). Devido à complexidade e o tamanho os projetos podem ser definidos como uma atividade multifuncional, pois o gerenciamento de projetos é estabelecido para concluir metas e objetivos específicos e 6 considera para isso o planejamento, a organização, a direção e o controle dos recursos da empresa na execução de um objetivo em relativo curto prazo (Kerzner, 2011).

A estratégia do projeto não deve ser limitada para servir apenas uma única organização, deve reconhecer a autonomia, bem como a sua posição única como parte de um contexto complexo em relação aos níveis de gestão do projeto e envolver não apenas os níveis operacionais e táticos, mas também o nível institucional para permitir a interação significativa com o contexto de negócios (Artto et al., 2008). Oliveira et al., (2016) contataram que o crescimento do gerenciamento de projetos no Brasil pode ser confirmado pelos seguintes aspectos:

- Relacionado às associações profissionais que vem ganhando espaço e se multiplicando.

- Devido à frequência de realização de simpósios, seminários e congressos sobre a temática exclusiva do gerenciamento de projetos.

- De acordo com a perspectiva associada, as escolas de administração de empresas que ofertam programas de pós-graduação em gerenciamento de projetos, em cursos que atraem público de diferentes formações.

- Pela quantidade de profissionais que buscam obter certificações profissionais com foco na disciplina do gerenciamento de projetos.

- Pelos investimentos das empresas na capacitação dos colaboradores, na criação de escritórios de projetos, na implantação de gestão de portfólios e programas, na mensuração do nível de maturidade em gerenciamento de projetos e na implantação de softwares específicos.

Para Vargas (2009), projeto é uma combinação de recursos da empresa, os quais trabalham em conjunto para criar ou desenvolver um produto que não existia anteriormente, com o objetivo de melhorar o desempenho no planejamento e na realização das estratégias organizacionais. É um empreendimento não repetitivo que se caracteriza pela clareza e lógica, com início, meio e fim, que se destina a atingir um objetivo bem definido, sendo conduzido por pessoas dentro de parâmetros predefinidos de tempo, custo, recursos envolvidos e qualidade. 


\section{REESTILIZAÇÃO DE UM VEÍCULO SÉRIE POR MEIO DA PINTURA AUTOMOTIVA BITON}

\subsection{DESCRIÇÃO DO CONTEXTO}

A indústria em estudo é do segmento automobilístico e se encontra instalada em uma planta da cidade de Porto Real, no estado do Rio de Janeiro. Trata-se de uma empresa com responsabilidades ambientais e engajamento social a fim de garantir a ética, a saúde e segurança dos funcionários além da proteção ao meio ambiente. A automotiva instalada em Porto Real iniciou um projeto para desenvolver a reestilização de um veículo série, já existente no mercado, por meio da pintura automotiva biton, que teve seu lançamento em nove meses. Esta indústria possui cinco modelos diferentes em linha além de uma variação de motores para o mercado local e exportação. Três diferentes marcas são produzidas com capacidade de 28 veículos por hora. A planta da empresa instalada em Porto Real é composta pelo setor administrativo, o prédio de produção de motores, a área de gestão de peças de reposição e fim de série e as três áreas da produção do veículo, sendo:

- Chaparia: processo de estruturação da carroceria. É responsável por cerca de $60 \%$ do produto acabado e se divide em estampagem e funilaria. A montadora hoje, não apresenta processo de estamparia de modo que recebe as peças já moldadas e realiza-se apenas a soldagem, união de painéis, acabamentos e reforços (Figura 2).

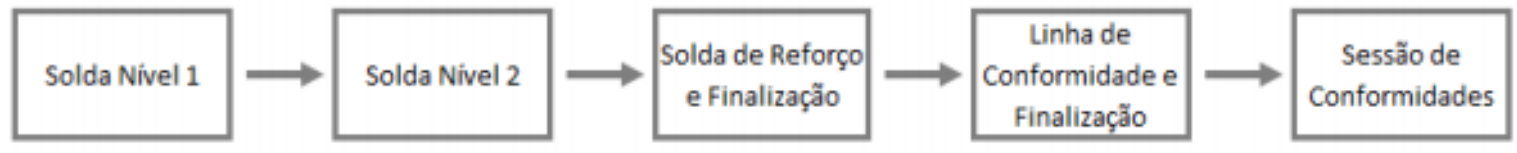

Figura 2 - Fluxograma Chaparia.

Esse processo ocorre em duas linhas separadas, partes móveis e carrocerias, mas seguem o mesmo sentido e ao final são unidas, controladas e enviadas ao processo de pintura.

- Pintura: processo de pintura da carroceria. É o processo onde é realizado o tratamento da chapa, vedação, pintura e acabamento com a finalidade de proteção, estanqueidade da carroceria, pigmentação da mesma e finalização (Figura 3).

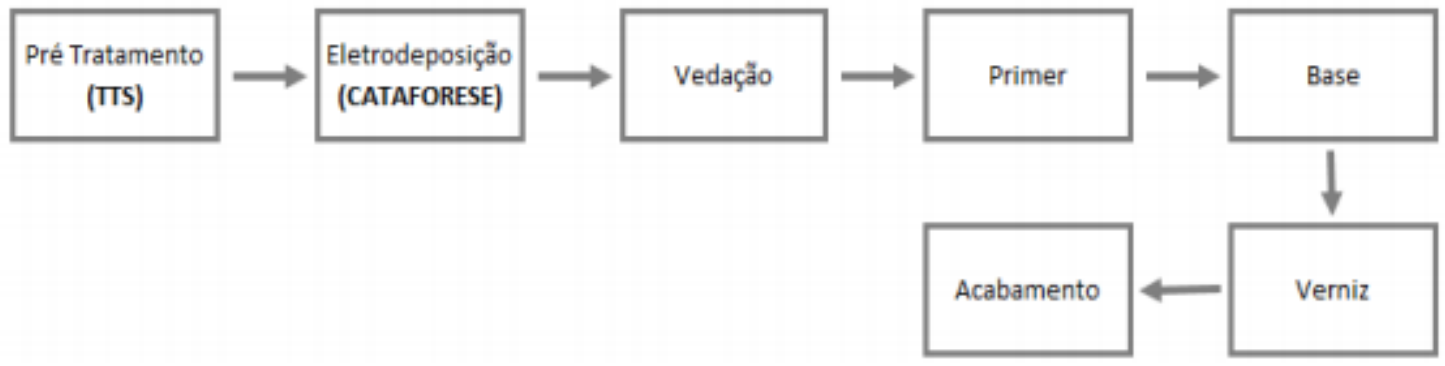

Figura 3 - Fluxograma Pintura.

Trata-se do processo mais complexo e delicado da planta da montadora, pois exige controle minucioso de limpeza, temperatura, composição química e camada de aplicação afim de 8 garantir a excelência na qualidade do produto. Ao final da linha, após seu controle 
no acabamento os veículos são enviados à montagem. Biton é o termo utilizado pela empresa para os veículos que apresentam duas cores de pintura, ou seja, a carroceira de uma cor e o teto de outra. Esse processo na montadora estudada pode ser considerado como uma repintura, isto é, o veículo é pintado normalmente com sua primeira cor, a cor da carroceria, e em seguida desviado do fluxo normal para uma linha exclusiva de modelos biton, onde manualmente é realizado o mascaramento do veículo, por meio de plásticos e fita, deixando o teto exposto (a parte que levará a segunda cor) e cobrindo a região que se manterá da cor já pintada anteriormente. Após essa camuflagem (Figura 4) o veículo segue para uma cabine de pintura, também manual, onde os operadores executam a pintura da segunda cor. O carro é curado em uma estufa e resfriado por meio de ventiladores, em seguida passa para o próximo posto, onde mais dois operadores realizarão o desmascaramento (retirarão os plásticos e fitas), o controle da pintura, a aplicação de adesivos e logos para acabamento. Finalizando todo esse procedimento o veículo está pronto para voltar ao fluxo normal de produção, onde realizarão sua montagem.

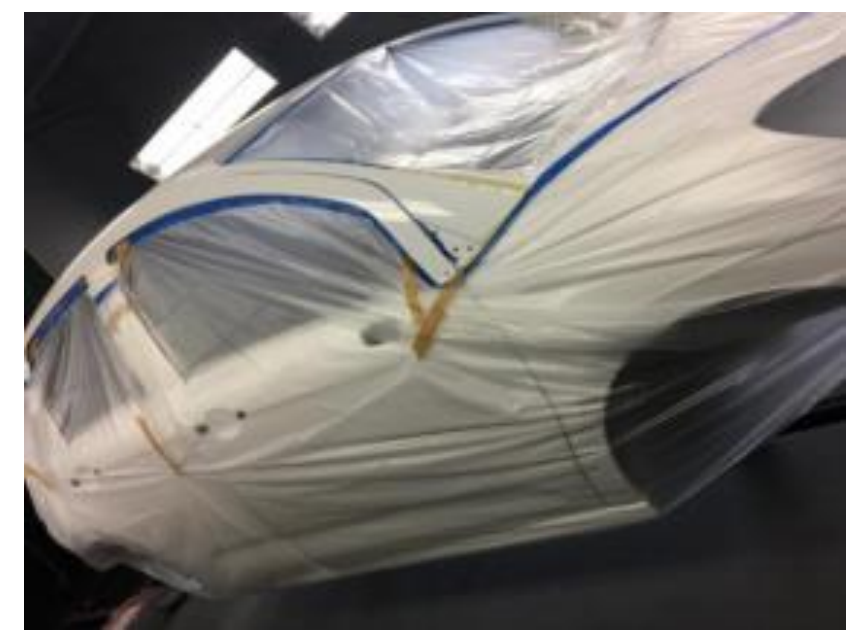

Figura 4 - Carro Biton Camuflado (Imagem cedida pela empresa, 2019).

- Montagem: processo de transformação do veículo. É responsável por toda caracterização do carro, onde o mesmo recebe sistemas elétricos e eletrônicos, suspensão, sensores, pneus, motor, painéis, vidros, bancos, entre outros. Na montadora, a linha se subdivide em duas, montagem das portas e montagem do veículo, unindo os dois no final do processo (Figura 5). O veículo é finalizado, passando pelo processo de estanqueidade em duchas e pela área da qualidade, tornando-se pronto para venda.

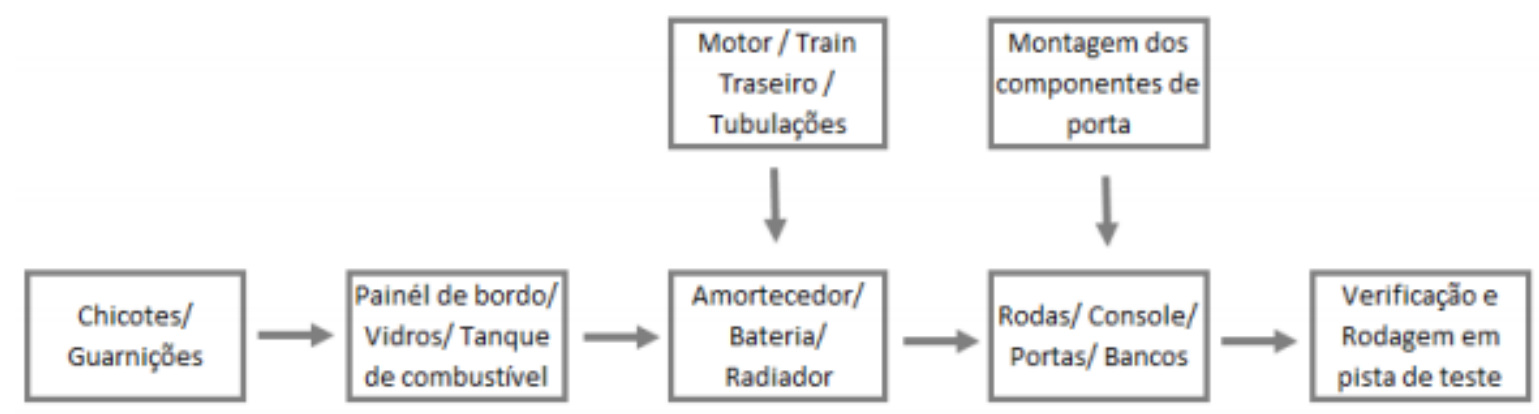

Figura 5 - Fluxograma Montagem. 


\section{RESULTADOS E DISCUSSÕES}

Na década de 1950, chamado de saia e blusa, o uso de duas cores em um mesmo veículo vem tomando conta do mercado nos novos SUV, denominados biton. O biton vem sendo trazido pela maioria das montadoras através da diferença de cores entre a carroceria e seu o teto. Se trata de um processo totalmente artesanal e extremamente delicado, demandando elevado tempo e altos custos, o que é possível notar nas concessionárias, pois acaba refletido no bolso do cliente. Devido a complexidade dos processos de pintura vários problemas surgiram, este estudo destaca os problemas e soluções referentes a qualidade encontrados na implantação do projeto.

O gerenciamento da qualidade dentro da montadora de Porta Real para os lançamentos industriais atrelados ao processo produtivo é baseado no procedimento denominado Qualificação de Processo (QdP). Se trata de uma matriz de qualidade onde uma grade com todos os itens do referencial da empresa são aplicados e em conjunto com a equipe de processo, o responsável da qualidade define metas, objetivos e indicadores (KPI's) a serem atingidos a cada etapa do projeto.

Em cada fase, uma reunião foi realizada com a equipe de projetos, onde toda a grade foi repassada e os objetivos anteriormente definidos foram analisados com o foco no resultado. Ao fim, é dado um parecer pelo responsável da qualidade, podendo ser Verde, se os objetivos tiverem sidos atingidos, Laranja, caso aja algum item em alerta ou Vermelho, caso os resultados apresentados não tenham sido satisfatórios (Figura 6). Caso o parecer seja Vermelho, o projeto está bloqueado para seguir para a próxima fase, tendo então que ser traçado um plano de ação urgente afim de corrigir os problemas encontrados. 


\section{Objetivo: Lançamento Principal}

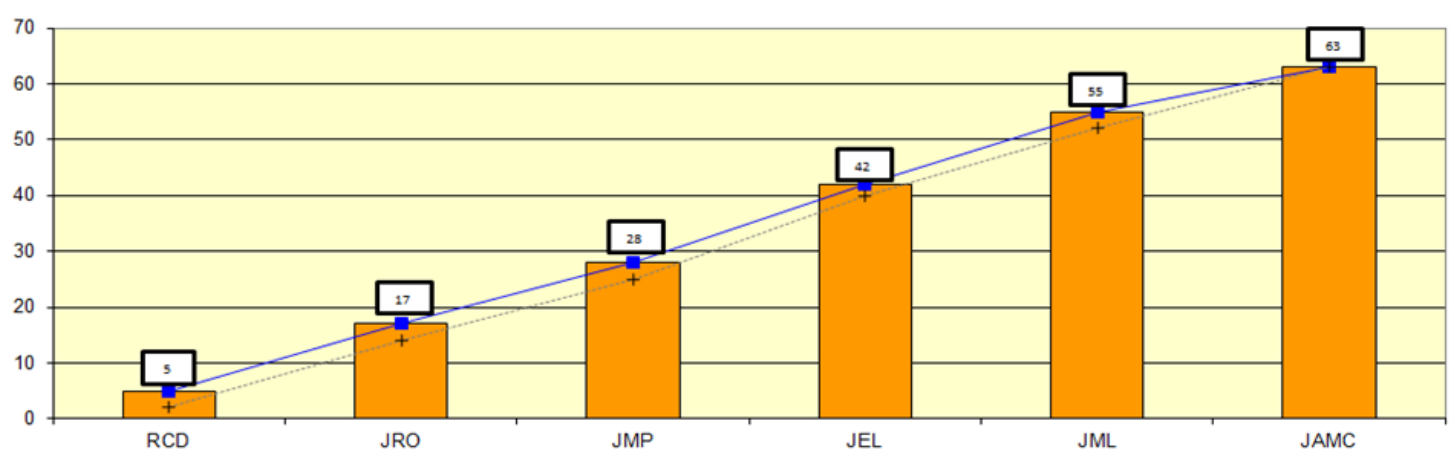

\section{Resultado Atual}

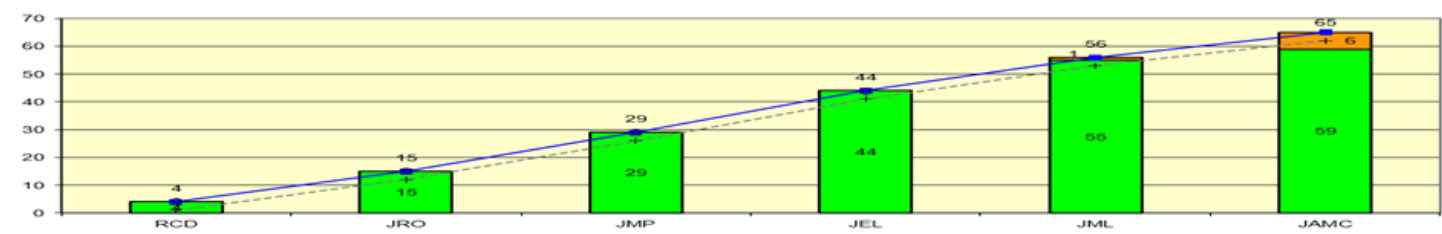

\begin{tabular}{|l|r|r|r|r|r|r|}
\hline ETAPAS DO PROJETO/EXIG ÊNCIAS & \multicolumn{1}{|c|}{ RCD } & \multicolumn{1}{|l|}{ JRO } & \multicolumn{1}{l|}{ JMP } & \multicolumn{1}{l|}{ JEL } & \multicolumn{1}{c|}{ JML } & \multicolumn{1}{c|}{ JAMC } \\
\hline Número de Exigências & $\mathbf{4}$ & $\mathbf{1 1}$ & $\mathbf{1 4}$ & $\mathbf{1 5}$ & $\mathbf{1 2}$ & $\mathbf{9}$ \\
\hline Acumulado de Exigências & 4 & 15 & 29 & 44 & 56 & 65 \\
\hline Pontos Laranjas (Em alerta) & 1 & 12 & 26 & 41 & 53 & 62 \\
\hline Acumulado Exigências Cumpridas & 4 & 15 & 29 & 44 & 55 & 59 \\
\hline Objetivos Pontos Laranjas (inferior) & $25 \%$ & $80 \%$ & $90 \%$ & $93 \%$ & $95 \%$ & $95 \%$ \\
\hline Acumulado & 4 & 15 & 29 & 44 & 56 & 65 \\
\hline Laranja & 0 & 0 & 0 & 0 & 1 & 6 \\
\hline Eficácia Laranja & $0 \%$ & $0 \%$ & $0 \%$ & $0 \%$ & $2 \%$ & $9 \%$ \\
\hline Eficácia Verde (OK) & $100 \%$ & $100 \%$ & $100 \%$ & $100 \%$ & $98 \%$ & $91 \%$ \\
\hline
\end{tabular}

Figura 6 - Grade Qualificação de Processo (Imagem cedida pela empresa, 2019).

O gerente de projeto é responsável por gerenciar toda a grade, ou seja, todos os itens existentes no referencial de qualidade da empresa, além dos objetivos e metas que foram definidos para a Qualificação de Processo. É essencial que tudo seja gerenciado de perto para que todas as fases do projeto sejam fechadas com parecer Verde. Ao final, é feita uma análise geral de todas as fases e emitido um parecer geral da equipe de qualidade onde é obtida uma autorização para o lançamento do veículo.

Para o projeto do veículo Biton foram definidos quatro KPI's para composição da grade de Qualificação de Processo, onde a equipe de projeto pintura era responsável pela alimentação e gerenciamento desses indicadores. São eles:

\section{- Bom Direto Biton}

O indicador 'Bom Direto Biton' (Figura 7) é o gráfico que apresenta a porcentagem de veículos com zero defeitos. $\mathrm{O}$ indicador apresenta os veículos com qualidade alcançada, quando sai do processo biton já de acordo com o referencial para enviar o veículo a montagem. Se trata do principal indicador para um projeto veículo, pois indica o nível de qualidade, uma das maiores exigências da fábrica. 


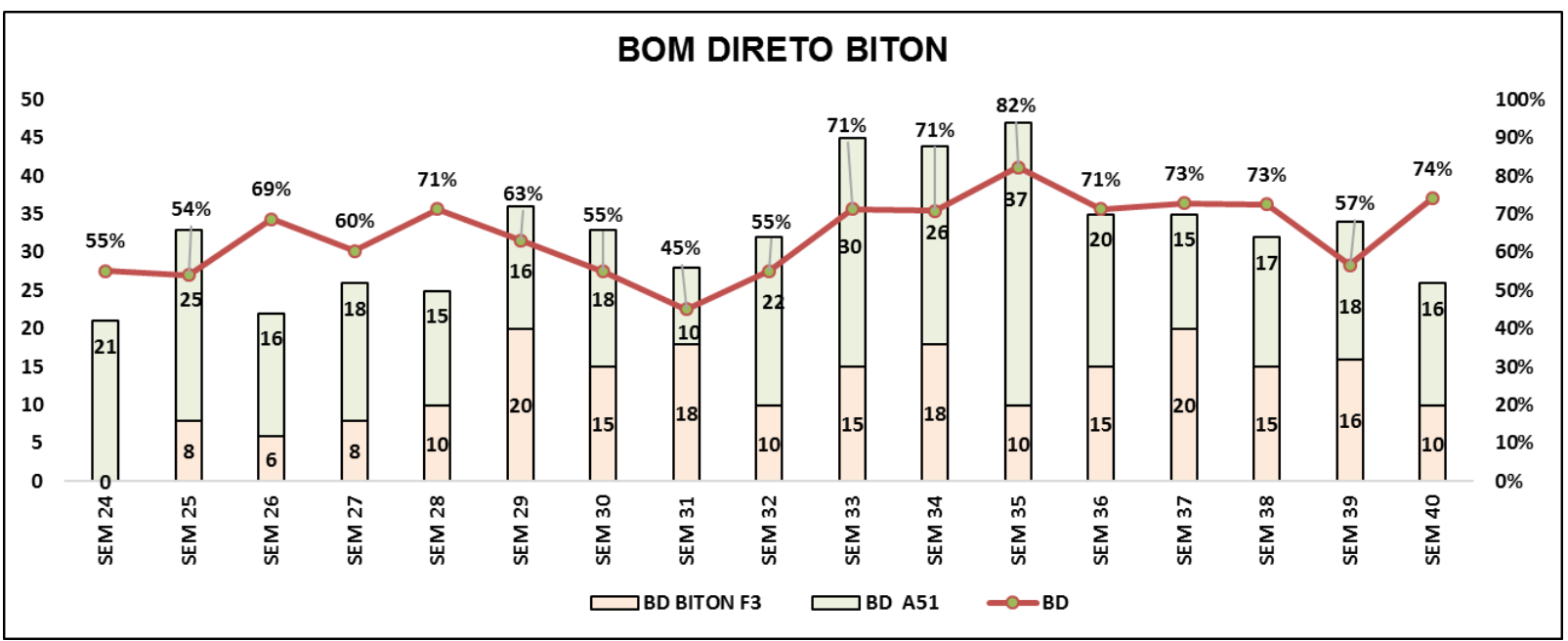

Figura 7 - KPI's Bom Direto (Imagem cedida pela empresa, 2019).

Os dados são coletados diariamente porem compilados apenas ao final de cada semana para alimentação do indicador. Dessa forma, cada barra do gráfico apresenta o somatório dos defeitos gerados na semana, SEM 24 por exemplo, representa os defeitos nos veículos produzidos durante a vigésima quarta semana do ano, e assim, sucessivamente.

Foi possível analisar que a média dos resultados ao longo de todo o projeto ficou em torno de $60 \%$, o que representa um resultado muito ruim, visto que o objetivo do indicador 'Bom Direto' é de $93 \%$.

\section{- Quantidade de Defeitos em Linha}

O indicador 'Quantidade de Defeitos em Linha' (Figura 8) foi construído para analisar a quantidade de defeitos do processo biton identificado pelos operadores da linha de controle da pintura.

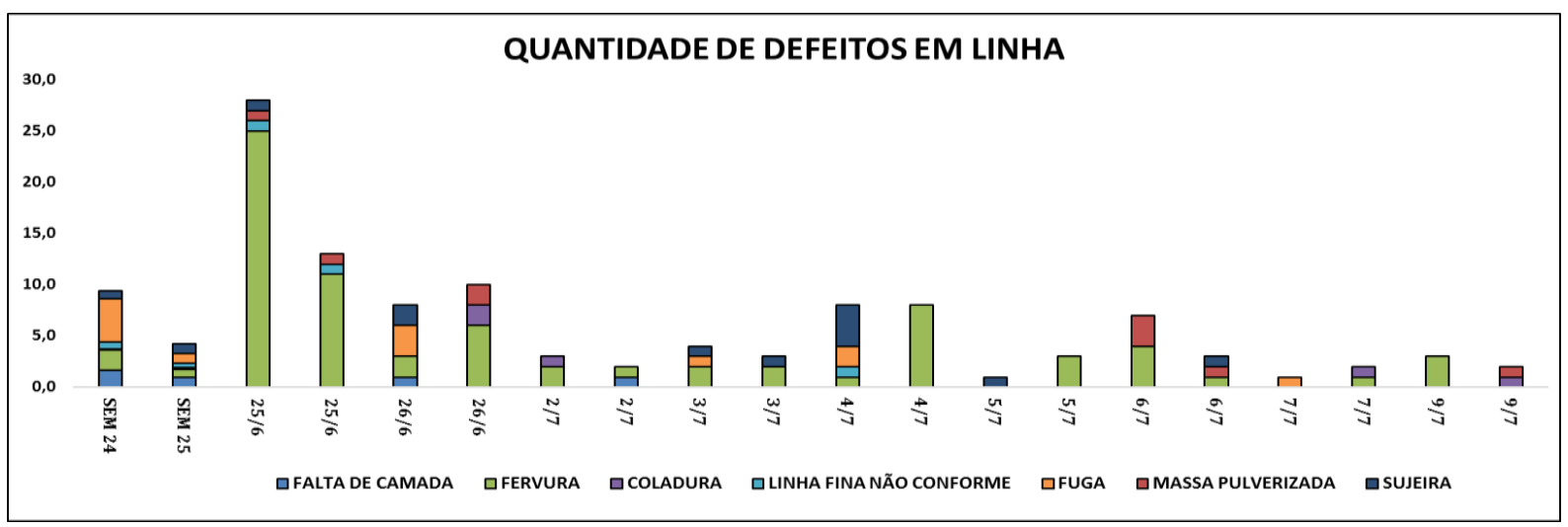

Figura 8 - KPI's Quantidade de Defeitos em Linha (Imagem cedida pela empresa, 2019).

A partir das análises realizadas nesse KPI, foi possível identificar que o principal defeito era a Fervura, excesso de tinta aplicado pelos operadores da cabine de pintura que ao curar gera bolhas sobre a carroceria, seguido da Linha Fina, acabamento no interior da porta. É considerado um indicador chave, pois após esse levantamento dos principais problemas os operadores da pintura são orientados para melhoria da qualidade.

\section{- Tempo de Retoque}

O indicador 'Tempo de Retoque' (Figura 9), foi definido para analisar o tempo que o veículo biton com defeito, ou seja, não era 'Bom Direto' demorava para ser retrabalhado. 
Através desse KPI é possível verificar o impacto que um veículo biton com problemas de qualidade provoca na linha e na cabine de retoque afim de conscientizar os operadores da importância de garantir a excelência.

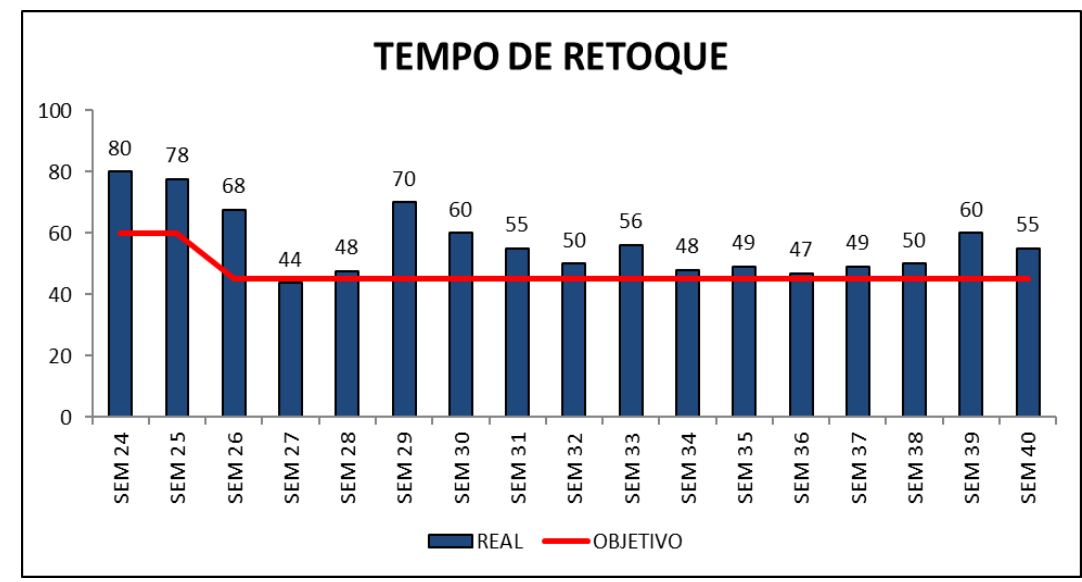

Figura 9 - KPI's Tempo de Retoque (Imagem cedida pela empresa, 2019).

Analisando o indicador foi possível perceber que, praticamente, todas as semanas o tempo de retoque ultrapassou a linha de objetivo. Ou seja, ao longo de todo o projeto o objetivo de tempo de retoque não foi cumprido, devido ao problema de qualidade.

Além de todo o impacto provado na linha e na cabine de retoque, as carrocerias seguem um tempo máximo estipulado pelo fluxo para ficarem dentro dos prédios dos processos produtivos e não impactar o carregamento FIFO e nem o pagamento de peça de borda de linha. Dessa forma, todos esses pontos foram impactados, gerando problemas graves para diversos setores, como montagem e logística.

\section{- Número de Defeitos}

O indicador 'Número de Defeitos', apresenta o número de veículos com defeito que foram detectados pela qualidade, ou seja, não foram identificados ou tratados dentro da pintura. É um indicador de grande importância pois permite a equipe de processo de pintura ser orientada quanto aos níveis de defeito e referenciais de qualidade para o biton.

Devido ao processo ser totalmente desconhecido, manual, complexo e delicado, muitos problemas e dificuldades foram enfrentados ao longo do projeto. Muitas fases não atingiram os seus objetivos definidos, sendo julgados como Vermelho pela qualidade, onde a equipe de projeto da pintura precisou definir planos de ações e contenções, trabalhando dobrado para cumprir os referenciais visto que o projeto não podia sofrer atrasos. Foi necessário também a conscientização dos operadores contratados, mostrando que o engajamento e comprometimento com o projeto era essencial para o sucesso, afim de que a qualidade fosse alcançada mais rapidamente.

$\mathrm{O}$ projeto até o seu lançamento não obteve a qualidade exigida, para que os problemas não chegassem ao consumidor, mais dois operadores foram contratados auxiliando na contenção dos defeitos, os quais só foram eliminados quatro meses depois, com destreza e pratica. Nesse grande desafio enfrentado pela equipe de projeto da pintura, as maiores dificuldades encontradas foram o tempo do processo de mascaramento que foi estudado e vendido à diretoria da empresa, que consequentemente afetou a quantidade de operadores contratados e a qualidade.

Os estudos foram feitos baseados nos processos existentes em outras plantas do site, que já aplicavam o processo biton em outros modelos, porém quando aplicado na pratica em cima do veículo produzido em Porto Real, a complexidade era muito maior e, portanto, o 
tempo para aplicação do mascaramento muito superior aos dos estudos realizados. As análises apontavam que 12 minutos eram suficientes para que o carro estivesse mascarado, ou seja, dois operadores aplicariam todos os plásticos, fitas e espumas. Porém, ao trazer para Porto Real gastava-se em média 34 minutos.

Visto isso, ao longo do projeto, com o aumento da produção, não foi possível entregar a quantidade de carros estipulados pela direção da empresa. Um outro problema foi alcançar a qualidade exigida pelos referencias da empresa devido ao processo completamente manual, sensível e complexo. Frente a esses dois enormes problemas, foi negociado com a diretoria a contratação de mais dois operadores para auxiliar na produção dos veículos e melhoria da qualidade.

Após o lançamento do veículo no mercado o projeto teoricamente havia se encerrado, porém as atividades na pintura continuaram buscando melhorias e evoluções. Apenas quatro meses depois do lançamento os operadores conseguiram alcançar a destreza necessária para garantir a qualidade dos veículos sem nenhum tipo de retrabalho. $\mathrm{O}$ tempo de processo evoluiu, chegando a 22 minutos, o tempo estudado pelo projeto nunca foi alcançado. Os dois operadores contratados temporariamente, foram efetivados para que fosse possível produzir o volume solicitado pela marca.

\section{CONCLUSÕES}

Ao buscar inovações as marcas visam um design mais atrativo e sofisticado passando a trabalhar tecnologias de pintura como um fator de diferenciação afim de se destacar frente ao seu cliente. A cor é uma das características que não se deve ignorar, talvez uma das mais importantes devido a diferenciação, que vem ganhando cada dia mais a atenção do consumidor. O projeto em questão foi baseado na necessidade da montadora automobilística de Porto Real realizar um estudo para desenvolver a reestilização de um veículo série, já existente no mercado, por meio da pintura automotiva biton. Oito macroprocessos da pintura foram apresentados neste estudo, sendo: tratamento de superfície (TTS), cataforese, vedação, primer, base, verniz e acabamento, os essenciais e o biton, opcional.

$\mathrm{O}$ projeto passou por alto número de defeitos e tempo de retoque acima do esperado. $\mathrm{O}$ grande desafio enfrentado pela equipe de projeto da pintura, foi o tempo do processo de mascaramento, que afetou a quantidade de operadores contratados e a qualidade dos produtos. Com a contratação de mais dois colaboradores e destreza a fábrica conseguiu garantir a qualidade dos veículos sem nenhum tipo de retrabalho, sendo possível reduzir o tempo de produção em 12 minutos, passando de 34 minutos para 22 minutos.

Este estudo de caso aplicou a metodologia de gerenciamento de projetos do PMBOK no gerenciamento da qualidade, apresentando os problemas encontrados e soluções. Nota-se que o gerenciamento da qualidade é fundamental nos projetos e essencial para melhoria de processos, ter uma equipe de projetos estruturada facilita alcançar os resultados esperados. $\mathrm{O}$ gerenciamento de custos pode ser abordado em estudos futuros.

\section{REFERÊNCIAS BIBLIOGRÁFICAS}

[1] ARCHIBALD, R. Managing High-Technology Programs and Projects, John Wiley and Sons, USA, p. 396, 2003.

[2] ARTTO, K., KUJALA, J., DIETRICH, P. e MARTINSUO, M. What is project strategy? International Journal of Project Management, vol. 26, n. 1, p. 4-12, 2008.

[3] CARVALHO, M. M., RABECHINI, J. R., PESSÔA, M. S. e LAURINDO, F. J. Equivalência e completeza: análise de dois modelos de maturidade em gestão de 
projetos. Revista de Administração da Universidade de São Paulo, vol. 40, n. 3, p. 289$300,2005$.

[4] CICMIL, S., WILLIAMS, T., THOMAS, J. e HODGSON, D. Rethinking project management: researching the actuality of projects. International Journal of Project Management, vol. 24, n. 8, p. 675-686, 2006.

[5] CONFORTO, E. C., SALUM, F., AMARAL, D. C., SILVA, S. L. e ALMEIDA, L. F. M. Can agile project management be adopted by industries other than software development? Project Management Jornal, vol. 45, n. 3, p. 21-34, 2014.

[6] HELDMAN, K. Gerência de Projetos: Guia para o Exame Oficial do PMI. $2^{\text {a }}$ Ed. - São Paulo: Campus, 2002.

[7] KEELING, R. Gestão de Projetos: Uma Abordagem Global $1^{a}$ ed; tradução Cid Knipel Moreira, São Paulo, Saraiva 2002.

[8] KERZNER, H. Gerenciamento de Projetos: uma abordagem sistêmica para planejamento, programação e controle. São Paulo: Blucher, 2011.

[9] MORRIS, P. W. G. Research and the future of project management. International Journal of Managing Projects in Business, vol. 3, n.1, p. 139-146, 2010.

[10] NACH, H. "Project management 2.0: Towards the renewal of the discipline." Strategic Integration of Social Media into Project Management Practice, p. 1-15, 2016.

[11] OLIVEIRA, R. R., BOLDORINI, P. S. A. T., MARTINS, H. C. e DIAS, A. T. Comparativo bibliométrico dos anais de congressos brasileiros na área de administração e engenharia de produção. Gestão e Projetos: GeP, vol. 7, n. 1, p. 15-31, 2016. ISSN-e 2236-0972.

[12] PMI, Guia do Conjunto de Conhecimentos em Gerenciamento de Projetos, ou Guia PMBOK, 6 ${ }^{\mathrm{a}}$ edição, 2017.

[13] TUNER, R. The Nine Schools of Project Management. In: Special Eden Doctoral Seminar - ESCLille. Proceedings, Lille (France), 2008.

As Referências Bibliográficas devem seguir as normas da ABNT/NBR 6023. 